\title{
Global existence and asymptotic behavior for a generalized Boussinesq type equation without dissipation
}

\author{
Guowei Liu ${ }^{1}$, Wei Wang ${ }^{1}$, and Qiuju $\mathrm{Xu}^{1}$ \\ ${ }^{1}$ Chongqing Normal University
}

September 25, 2021

\begin{abstract}
In this paper, we study the Cauchy problem for a generalized Boussinesq type equation in $\$ \backslash$ mathbb $\{\mathrm{R}\}^{\wedge} n \$$. We establish a dispersive estimate for the linear group associated with the generalized Boussinesq type equation. As applications, the global existence, decay and scattering of solutions are established for small initial data.
\end{abstract}

\section{Hosted file}

Manuscript For M2.pdf available at https://authorea.com/users/437669/articles/539146-globalexistence-and-asymptotic-behavior-for-a-generalized-boussinesq-type-equation-withoutdissipation

\section{Hosted file}

Manuscript For M2.tex available at https://authorea.com/users/437669/articles/539146-globalexistence-and-asymptotic-behavior-for-a-generalized-boussinesq-type-equation-withoutdissipation 